\title{
Assessment of Industry Partners: Inputs for Partnership Improvement and Selection of Host Training Establishments
}

\author{
MA JASMINE J. DE GUZMAN \\ Program Chairperson, Business Administration Program, \\ Pangasinan State University \\ PHILIPPINES
}

\begin{abstract}
Industry partners such as energy providers (in electric Power Systems for example) are critical in the successful implementation of the University's internship program and attainment of objectives. Thus, it is important that the University adhere to the criteria and requirements outlined by the Commission on Higher Education for selection of reputable host training establishments. This study aims to provide additional guidelines for the Business Administration program in considering prospective industry partners for internship by
\end{abstract}

incorporating the students' assessment of industry partners. Using independent samples t-test, the researcher found that the profile of the industry partner has no significant effect on the level of implementation, the students' feedback, attainment of objectives and the seriousness of problems encountered during internship. Through independent samples t-test and One-Way ANOVA, it was found that the students' profile also has no effect on the perceived seriousness of problems encountered during the training. However, using Pearson correlation coefficient analysis, it was found that the level of implementation of the internship program within the industry partner has a relationship with the students' feedback, level of attainment of in ternship objectives, and the seriousness of problems encountered. The level of implementation positively impacts the level of attainment of objectives and the seriousness of problems encountered. While the relationship with feedback was generally positive, it was found that the level of implementation negatively impacts the students' feedback of industry partners in terms of decision making and empowerment.

Key-Words: Electric Power, Electric Energy, Power Systems, Industry partner, academe-industry relationship, Received: December 29, 2020. Revised: April 17, 2021. Accepted: April 30, 2021. Published: May 4, 2021.

\section{Introduction}

An industry is a group of businesses engaged in the production of closely related goods or services within an economy such as electric providers and other business establishments [1]. There are various ways in which academic institutions engage with industry partners. This includes training, teaching, research, exchange of knowledge and technology transfers. Our study is very important in Electric Power Systems, Electric Energy, Electric Vehicles Industry etc. In Philippines, the stagnant situation of academeindustry partnership [1] is marked by the limited practice of collaboration most commonly in the areas of on-the-job trainings, graduate placement, and curriculum design. These partnerships are mostly initiated by the faculty members and officials of the universities who have established personal contacts with key people working for industry partners[2].

The ubiquity of collaboration between universities and industry partners in the area of internship is attributed to the policy of the Commission on Higher Education (CHED) requiring higher education institutions (HEIs) to establish strong academic linkages with business and industry to provide students with competitive skills and attitudes for employment. HEIs are required to partner with a "reputable" host training establishment (HTE) - duly accredited government agencies and commercial establishments registered with the Securities and Exchange Commission (SEC) and the Department of Trade and Industry (DTI) with a well-established training system $[3,4]$. The partnership between the academic institution and industry partner is formalized through a memorandum of agreement executed by both parties specifying the detailed role and responsibilities of concerned parties, safety of student interns, training plan, learning objectives and method of evaluation. This collaboration is geared towards producing positive results eventually leading to attainment of the internship program objectives outlined by CHED [4-8], [16,17]. Our study is very important in Electric Power Systems and can find numerous applications in Electric Energy, Electric Vehicles Industry, Electric Economy etc.

Both the academe and industry benefit from these partnerships. Mutual benefits provided to collaborating universities and industry partners supports the assertion that both are engaged in a win- 
win kind of a relationship [9-11]. Collaboration with industry is critical for academia to create scientific knowledge and obtain industrial data. In turn, collaboration with universities is crucial for organizations in joint, scientific-based research projects in order to develop solutions for productionsourced problems. Valuable academe-industry partnerships are those that produce and share new knowledge that drives innovation within both the academe and the industry inducing benefits that will be useful for the society.

The Business Administration program of Pangasinan State University Lingayen Campus is partnered with government institutions and private establishments in providing the students a curriculum-based work integrated learning $[12,13]$. Business administration students are required to render 400 hours of internship. The students who underwent on-the-job training for SY 2019-2020 were posted across seventeen (17) organizations - thirteen (13) government agencies and four (4) commercial establishments - located in Pangasinan and Baguio. The industry partners are actively involved in evaluating student performance during training. The supervisor's student performance evaluation constitutes a portion of the intern's grade. Likewise, the students evaluate the industry partners and their overall internship experience upon the completion of their training.

The researcher aims to build on the criteria and minimum requirements outlined by CHED in selecting a reputable HTE to create a more robust assessment of industry partners by way of incorporating the students' perspective of the training experience received from HTE. This study focuses on the students' perceived level of implementation of internship program within their assigned industry partners, ability of their assigned industry partner as a credible training support provider in areas of collaboration and teamwork, communication, dealing with people, decision making and empowerment, and work ethics, and seriousness of encountered problems in considering an assessment and evaluation of the industry partners from the student-intern's perspective [14].

\subsection{Statement of the Problem}

The study aims to assess the Business Administration program's industry partners in terms of the studentintern's perspective. It endeavours to explore what essential characteristics of the industry partners are driving the student-intern's assessment and evaluation. Specifically, the research aims to (1) test the difference in level of implementation of the internship program within PSU and the industry partner; (2) test the difference in the level of implementation among industry partners along the industry partners' characteristics; (3) test the difference in the students' feedback on industry partners grouped according to their profile; (4) test the difference in the level of attainment of objectives among various groups of industry partners; (5) test the difference in the seriousness of problems encountered by interns when industry partners are grouped based on their profile; and (6) determine the relationship between the level of implementation of internship program, students' feedback on industry partner, attainment of internship objectives, and seriousness of problems encountered.

\subsection{Significance of the Study}

This study builds on the initial research conducted by the author describing the implementation of the internship program within PSU and the industry partner, the students' feedback on industry partners, level of attainment of internship programs and the seriousness of encountered problems during internship. This research offers a deeper understanding for the program in evaluating its industry partners adding another dimension to regulatory requirements. In addition to enhancement of learning from internship program, this provides the department a template for sound decision-making in deployment of the student-interns, improvement of continuing partnership, and selection for choosing new HTEs for expanding linkages. The researcher also aims to be a catalyst in providing important insights to the University on the status of its internship program. This also adds to the growing body of knowledge investigating the importance of academe-industry partnerships.

\section{Research Methodology}

This study is an extension of the author's research focusing on the Business Administration program's student interns [15]. This furthers the study objectives through the use of a quantitativecorrelational approach using the data from the author's aforementioned work. Appropriate statistical techniques were used on the results from the survey questionnaire in attempting to differentiate the implementation of internship program between the university and industry partner; the effect of industry profile variables on the perceived effectiveness of implementation of internship programs, the intern's feedback on the training support provided, and the seriousness of problems encountered; and investigate the relationship of the industry partner's level of implementation of 
internship program on the students' feedback, attainment of internship objectives and seriousness of problems encountered during internship.

\subsection{Sources of Data and Processing}

The data used in this study was obtained from the author's concurrent research. The said research collected primary data from the survey questionnaire accomplished by conveniently sampled Business Administration interns for SY 2019-2020. The data was extracted to a Microsoft Excel file (.xlsx) and imported into IBM SPSS for statistical analysis. The output of the analysis was extracted to an Excel file and prepared for presentation of results.

\subsection{Statistical Treatment Used}

Statistical analysis was conducted on IBM SPSS. Independent Samples t-test was used to determine the difference between PSU and industry partners in terms of level of implementation. It was also employed to test the difference between students' feedback, attainment of objectives, and seriousness of problems encountered during internship. A combination of independent samples t-test and OneWay Analysis of Variance was used to test the difference between seriousness of problems encountered by interns when grouped according to the industry partner's profile.

Pearson correlation analysis was conducted to test the relationship between the level of implementation, the students' feedback on industry partners, level of attainment of internship objectives, and the seriousness of problems encountered. A correlation matrix was created to present the results of the analysis conducted.

\section{Results and Discussion}

The results of the independent samples t-test conducted to investigate the difference between the level of implementation of the internship program between PSU and its industry partner are presented in Table 1. PSU incurred a slightly higher mean rating of 3.67 compared to the industry partner which incurred a mean rating of 3.65. The test incurred a pvalue of greater than 0.05 which leads to the acceptance of the null hypothesis that there is no significant difference between the level of implementation of internship objectives between PSU and industry partners.

Table 1. Difference between PSU and Industry Partner in terms of Level of Implementation

\begin{tabular}{ccccccccc}
\hline $\begin{array}{c}\text { Level of } \\
\text { Implementation }\end{array}$ & N & Mean & SD & t & $\mathbf{p}$ & $\begin{array}{c}\text { Cohen's } \\
\mathbf{d}\end{array}$ & Decision & Interpretation \\
\hline PSU & 112 & 3.67 & 0.44 & 0.28 & 0.78 & 0.04 & Accepted & Not Significant \\
Industry Partner & 112 & 3.65 & 0.47 & & & & & \\
\hline
\end{tabular}

Table 2 presents the results of the analysis conducted whether or not there is a difference between level of implementation of internship program among industry partners when grouped according to their profile variables. The results yielded p-values of greater than 0.05 across all industry partner profile variables of type, years of operation and location relative to student-trainee's place of residence. Thus, the null hypothesis that there is no significant difference in the mean ratings for level of implementation among industry partners when grouped according to profile variables is accepted. The level of implementation is the same whether it is a business/commercial establishment or a government institution. The same goes for the level of implementation in newer industry partners and older industry partners. Distance does not make any difference on the level of implementation of internship program.

Table 2. Difference on Level of Implementation When Grouped According to Industry Partner Profile Variables

\begin{tabular}{lcccccccc}
\hline \multicolumn{1}{c}{ Industry Partner Profile } & N & Mean & SD & t & p & $\begin{array}{c}\text { Cohen's } \\
\mathbf{d}\end{array}$ & Decision & Interpretation \\
\hline $\begin{array}{l}\text { Type } \\
\quad \begin{array}{l}\text { Business/Commercial } \\
\text { Establishment }\end{array}\end{array}$ & 30 & 3.64 & 0.59 & -0.19 & 0.85 & -0.04 & Accepted & Not Significant \\
$\quad$\begin{tabular}{l} 
Government Institution \\
\hline
\end{tabular} & 82 & 3.66 & 0.41 & & & & & \\
\hline
\end{tabular}

Years of Operation 


\begin{tabular}{lrrrrrrrr} 
Below Mean & 71 & 3.61 & 0.44 & -1.37 & 0.17 & -0.26 & Accepted & Not Significant \\
Above Mean & 41 & 3.73 & 0.50 & & & & & \\
\hline Location of Industry Partner Relative to Student & Trainee's Address & & & \\
Within & 34 & 3.60 & 0.44 & -0.85 & 0.40 & -0.16 & Accepted Not Significant \\
Outside & 78 & 3.68 & 0.47 & & & & & \\
\hline
\end{tabular}

Table 3 presents the results of the analysis conducted whether or not there is a difference between industry partners in terms of the students' feedback on collaboration and teamwork. An independent samples t-test was done across all profile variables to test the hypothesis.

Table 3. Difference on Interns' Feedback on Industry Partner in terms of Collaboration and Teamwork When Grouped According to Industry Partner Profile Variables

\begin{tabular}{|c|c|c|c|c|c|c|c|c|}
\hline Industry Partner Profile & $\mathbf{N}$ & Mean & SD & $\mathbf{t}$ & $\mathbf{p}$ & $\begin{array}{c}\text { Cohen's } \\
\text { d }\end{array}$ & Decision & Interpretation \\
\hline \multicolumn{9}{|l|}{ Type } \\
\hline $\begin{array}{l}\text { Business/Commercial } \\
\text { Establishment }\end{array}$ & 30 & 3.77 & 1.25 & -0.72 & 0.47 & -0.14 & Accepted & Not Significant \\
\hline Government Institution & 82 & 3.95 & 1.22 & & & & & \\
\hline \multicolumn{9}{|l|}{ Years of Operation } \\
\hline Below Mean & 71 & 3.76 & 1.25 & -1.65 & 0.10 & -0.31 & Accepted & Not Significant \\
\hline Above Mean & 41 & 4.15 & 1.15 & & & & & \\
\hline \multicolumn{9}{|c|}{ Location of Industry Partner Relative to Student Trainee's Address } \\
\hline Within & 34 & 3.74 & 1.28 & -0.92 & 0.36 & -0.18 & Accepted & Not Significant \\
\hline Outside & 78 & 3.97 & 1.20 & & & & & \\
\hline
\end{tabular}

The results yielded p-values of greater than 0.05 across all industry partner profile variables of type, years of operation and location relative to studenttrainee's place of residence. Thus, the null hypothesis that there is no significant difference in the mean ratings for students' feedback on industry partner with regards to collaboration and teamwork is accepted. The feedback on collaboration and teamwork is the same whether it is a business/commercial establishment or a government institution. The same goes for the feedback among newer industry partners and older industry partners. Distance does not make any difference on the feedback regarding collaboration and teamwork within industry partners.

Table 4. Difference on Interns' Feedback on Industry Partner in terms of Communication When Grouped According to Industry Partner Profile Variables

\begin{tabular}{|c|c|c|c|c|c|c|c|c|}
\hline Industry Partner Profile & $\mathbf{N}$ & Mean & SD & $\mathbf{t}$ & $\mathbf{p}$ & $\begin{array}{l}\text { Cohen's } \\
\text { d }\end{array}$ & Decision & Interpretation \\
\hline \multicolumn{9}{|l|}{ Type } \\
\hline $\begin{array}{l}\text { Business/Commercial } \\
\text { Establishment }\end{array}$ & 30 & 3.66 & 1.32 & -0.31 & 0.76 & -0.06 & Accepted & Not Significant \\
\hline Government Institution & 82 & 3.74 & 1.24 & & & & & \\
\hline \multicolumn{9}{|l|}{ Years of Operation } \\
\hline Below Mean & 71 & 3.65 & 1.25 & -0.75 & 0.46 & -0.14 & Accepted & Not Significant \\
\hline Above Mean & 41 & 3.84 & 1.27 & & & & & \\
\hline \multicolumn{9}{|c|}{ Location of Industry Partner Relative to Student Trainee's Address } \\
\hline Within & 34 & 3.74 & 1.25 & 0.09 & 0.93 & 0.02 & Accepted & Not Significant \\
\hline Outside & 78 & 3.71 & 1.26 & & & & & \\
\hline
\end{tabular}


The results of the analysis to determine whether there is a difference on interns' feedback on industry partner in terms of communication when grouped according to industry partner profile variables is presented in Table 4. Based on the results of the analysis, the p-value for the difference between business/commercial establishment and government institution was 0.76 . This means that the null hypothesis that there is no significant difference between feedback of students in terms of communication when industry partners are grouped according to type is accepted. When grouped according to years of operation, those that have operated for more than the average registered a numerically higher mean than newer industry partners with 3.84 compared to 3.65 for the latter. The p-value was computed to be at 0.46 . This means that the null hypothesis is accepted as there is no statistically significant difference between mean ratings provided by students with regards to their feedback on industry partners' attitude towards communications. The industry partner located in the same city/municipality as the student's address registered a slightly higher mean rating for feedback on industry partners' attitude towards communication with 3.74 compared to those located outside the students' city/municipality of residence with 3.71. The p-value computed was found to be at 0.93 which means that the difference is not statistically significant.
Table 5 presents the results of the analysis conducted whether or not there is a difference between industry partners in terms of the students' feedback on their attitude on people management. An independent samples t-test was done across all profile variables to test the hypothesis. Based on the results of the analysis, the p-value for the difference between business/commercial establishment and government institution was 0.98. This means that the null hypothesis that there is no significant difference between feedback of students with regards to people when industry partners are grouped according to type is accepted. When grouped according to years of operation, those that have operated for more than the average registered a numerically higher mean than newer industry partners with 3.98 compared to 3.93 for the latter. The p-value was computed to be at 0.85 . This means that the null hypothesis is accepted as there is no statistically significant difference between mean ratings provided by students with regards to their feedback on industry partners' attitude towards people. The industry partner located in the same city/municipality as the student's address registered a slightly higher mean rating for feedback on industry partners' attitude towards communication with 3.96 compared to those located outside the students' city/municipality of residence with 3.94. The p-value computed was found to be at 0.92 which means that the difference is not statistically significant.

Table 5. Difference on Interns' Feedback on Industry Partner in terms of Regard for People When Grouped According to Industry Partner Profile Variables

\begin{tabular}{|c|c|c|c|c|c|c|c|c|}
\hline Industry Partner Profile & $\mathbf{N}$ & Mean & SD & $\mathbf{t}$ & $\mathbf{p}$ & $\begin{array}{c}\text { Cohen's } \\
\text { d }\end{array}$ & Decision & Interpretation \\
\hline \multicolumn{9}{|l|}{ Type } \\
\hline $\begin{array}{l}\text { Business/Commercial } \\
\text { Establishment }\end{array}$ & 30 & 3.94 & 1.26 & -0.02 & 0.98 & 0.00 & Accepted & Not Significant \\
\hline Government Institution & 82 & 3.95 & 1.21 & & & & & \\
\hline \multicolumn{9}{|l|}{ Years of Operation } \\
\hline Below Mean & 71 & 3.93 & 1.23 & -0.19 & 0.85 & -0.04 & Accepted & Not Significant \\
\hline Above Mean & 41 & 3.98 & 1.23 & & & & & \\
\hline \multicolumn{9}{|c|}{ Location of Industry Partner Relative to Student Trainee's Address } \\
\hline Within & 34 & 3.96 & 1.25 & 0.10 & 0.92 & 0.02 & Accepted & Not Significant \\
\hline Outside & 78 & 3.94 & 1.21 & & & & & \\
\hline
\end{tabular}

Table 6 shows the results of the analysis conducted to determine whether or not difference on interns' feedback on industry partner in terms of decision making and empowerment is statistically significant when grouped according to their profile variables.
The analysis shows that there is no statistically significant difference between the mean ratings of business/commercial establishments $(m=2.95)$ and government institutions $(\mathrm{m}=3.02)$ with $\mathrm{p}$-value equal to 0.78 . Also, despite industry partners operating for less than the average $(m=3.07)$ slightly edging out the 
older ones $(\mathrm{m}=2.87)$, it was found that the $\mathrm{p}$-value was 0.37 greater than 0.05 , the threshold for determining statistical significance. There is no statistical significance in terms of the difference between industry partners located within the city/municipality of residence of the student and industry partners located in another city/municipality despite the latter registering a mean of 3.05 slightly edging out the former with 2.88 . Therefore, the null hypothesis is accepted across three industry partner profile variables.

Table 6. Difference on Interns' Feedback on Industry Partner in terms of Decision Making and Empowerment When Grouped According to Industry Partner Profile Variables

\begin{tabular}{|c|c|c|c|c|c|c|c|c|}
\hline Industry Partner Profile & $\mathbf{N}$ & Mean & SD & $\mathbf{t}$ & $\mathbf{p}$ & $\begin{array}{l}\text { Cohen's } \\
\text { d }\end{array}$ & Decision & Interpretation \\
\hline \multicolumn{9}{|l|}{ Type } \\
\hline $\begin{array}{l}\text { Business/Commercial } \\
\text { Establishment }\end{array}$ & 30 & 2.95 & 1.20 & -0.28 & 0.78 & -0.05 & Accepted & Not Significant \\
\hline Government Institution & 82 & 3.02 & 1.12 & & & & & \\
\hline \multicolumn{9}{|l|}{ Years of Operation } \\
\hline Below Mean & 71 & 3.07 & 1.17 & 0.91 & 0.37 & 0.17 & Accepted & Not Significant \\
\hline Above Mean & 41 & 2.87 & 1.07 & & & & & \\
\hline \multicolumn{9}{|c|}{ Location of Industry Partner Relative to Student Trainee's Address } \\
\hline Within & 34 & 2.88 & 1.15 & -0.72 & 0.47 & -0.14 & Accepted & Not Significant \\
\hline Outside & 78 & 3.05 & 1.13 & & & & & \\
\hline
\end{tabular}

The results of the analysis to determine whether there is a difference on interns' feedback on industry partner in terms of work ethics when grouped according to industry partner profile variables is presented in Table 7. The analysis shows that there is no statistically significant difference between the mean ratings of business/commercial establishments $(\mathrm{m}=3.64)$ and government institutions $(\mathrm{m}=3.92)$ with p-value equal to 0.31 . Also, despite industry partners operating for more than the average $(m=3.94)$ slightly edging out the newer ones $(\mathrm{m}=3.79)$, it was found that the p-value was 0.55 greater than 0.05 , the threshold for determining statistical significance. There is no statistical significance in terms of the difference between industry partners located within the city/municipality of residence of the student and industry partners located in another city/municipality despite the latter registering a mean of 3.94 edging out the former with 3.62. Therefore, the null hypothesis is accepted across three industry partner profile variables.

Table 7. Difference on Interns' Feedback on Industry Partner in terms of Work Ethics When Grouped According to Industry Partner Profile Variables

\begin{tabular}{|c|c|c|c|c|c|c|c|c|}
\hline Industry Partner Profile & $\mathbf{N}$ & Mean & SD & $\mathbf{t}$ & $\mathbf{p}$ & $\begin{array}{l}\text { Cohen's } \\
\text { d }\end{array}$ & Decision & Interpretation \\
\hline \multicolumn{9}{|l|}{ Type } \\
\hline $\begin{array}{l}\text { Business/Commercial } \\
\text { Establishment }\end{array}$ & 30 & 3.64 & 1.36 & -1.02 & 0.31 & -0.19 & Accepted & Not Significant \\
\hline Government Institution & 82 & 3.92 & 1.24 & & & & & \\
\hline \multicolumn{9}{|l|}{ Years of Operation } \\
\hline Below Mean & 71 & 3.79 & 1.29 & -0.60 & 0.55 & -0.11 & Accepted & Not Significant \\
\hline Above Mean & 41 & 3.94 & 1.26 & & & & & \\
\hline \multicolumn{9}{|c|}{ Location of Industry Partner Relative to Student Trainee's Address } \\
\hline Within & 34 & 3.62 & 1.28 & -1.24 & 0.22 & -0.24 & Accepted & Not Significant \\
\hline Outside & 78 & 3.94 & 1.27 & & & & & \\
\hline
\end{tabular}


Table 8 presents the results of the independent samples t-test conducted to determine whether the difference in attainment of objectives of industry partners bear statistical significance when grouped according to industry partner profiles. When grouped according to type of establishment, government institutions registered a numerically higher mean rating of 4.54 compared to business/commercial establishments with 4.51. The p-value was found to be 0.76 which means that the difference is statistically insignificant. In terms of length of operation, those who have been around longer had a higher mean rating of 4.60 compared to newer industry partners with 4.49 . However, the p-value is found to be 0.30 which means that the difference is statistically insignificant. Industry partners located outside the city/municipality of student-trainee's residence registered a slightly higher level of attainment at 4.54 compared to industry partners within the city/municipality of student-trainee's residence with 4.52 . The p-value is computed to be
0.85 which means that the difference is insignificant. Thus, the null hypothesis that there is no significant difference in attainment of objectives between industry partners when grouped according to their profile is accepted.

The statistically insignificant results obtained from testing the difference between student interns' feedback of the industry partners' training support in the areas of collaboration and teamwork, communication, regards for people, decision making and empowerment, and work ethics contradicts the results of the study by An and Mauhay whose result supported the relationship of industry partners' profile variables such as the kind of industry, type of business, number of employees, and length of operation. [11] On the other hand, the results of the study supported the lack of influence of industry partner's location on the overall feedback of the student intern. [11]

Table 8. Difference on Level of Attainment of Internship Program Objectives When Grouped According to Industry Partner Profile Variables

\begin{tabular}{|c|c|c|c|c|c|c|c|c|}
\hline Industry Partner Profile & $\mathbf{N}$ & Mean & SD & $\mathbf{t}$ & $\mathbf{p}$ & $\begin{array}{l}\text { Cohen's } \\
\quad \text { d }\end{array}$ & Decision & Interpretation \\
\hline \multicolumn{9}{|l|}{ Type } \\
\hline $\begin{array}{l}\text { Business/Commercial } \\
\text { Establishment }\end{array}$ & 30 & 4.51 & 0.55 & -0.31 & 0.76 & -0.06 & Accepted & Not Significan \\
\hline Government Institution & 82 & 4.54 & 0.51 & & & & & \\
\hline \multicolumn{9}{|l|}{ Years of Operation } \\
\hline Below Mean & 71 & 4.49 & 0.54 & 0.52 & 0.30 & -0.20 & Accepted & Not Significan \\
\hline Above Mean & 41 & 4.60 & 0.48 & & & & & \\
\hline \multicolumn{9}{|c|}{ Location of Industry Partner Relative to Student Trainee's Address } \\
\hline Within & 34 & 4.52 & 0.59 & -0.19 & 0.85 & -0.04 & Accepted & Not Significan \\
\hline Outside & 78 & 4.54 & 0.49 & & & & & \\
\hline
\end{tabular}

Table 9 presents the results of the independent

difference in problems encountered during internship samples t-test conducted to determine whether the bear statistical significance when grouped according to industry partner profiles.

Table 9. Difference on Seriousness of Problems Encountered by Interns When Grouped According to Industry Partner Profile Variables

\begin{tabular}{lcccccccc}
\hline Industry Partner Profile & N & Mean & SD & t & p & $\begin{array}{c}\text { Cohen's } \\
\text { d }\end{array}$ & Decision & Interpretation \\
\hline $\begin{array}{l}\text { Type } \\
\quad \begin{array}{l}\text { Business/Commercial } \\
\text { Establishment }\end{array}\end{array}$ & 30 & 1.33 & 0.55 & 0.26 & 0.79 & 0.05 & Accepted & Not Significant \\
$\quad \begin{array}{l}\text { Government Institution } \\
\quad\end{array}$ & 82 & 1.30 & 0.47 & & & & & \\
\hline $\begin{array}{l}\text { Years of Operation } \\
\text { Below Mean }\end{array}$ & 71 & 1.31 & 0.50 & 0.12 & 0.90 & 0.02 & Accepted & Not Significant \\
\hline
\end{tabular}




\begin{tabular}{lllllllll} 
Above Mean & 41 & 1.30 & 0.46 & & \\
\hline Location of Industry Partner Relative to Student Trainee's Address & & & & \\
Within & 34 & 1.36 & 0.51 & 0.71 & 0.48 & 0.14 & Accepted Not Significant \\
Outside & 78 & 1.28 & 0.48 & & & & & \\
\hline
\end{tabular}

When grouped according to type of establishment, government institutions registered a numerically lower mean rating of 1.30 compared to business/commercial establishments with 1.33. The p-value was found to be 0.79 which means that the difference is statistically insignificant. In terms of length of operation, those who have been around longer had a lower mean rating of 1.30 compared to newer industry partners with 1.31. However, the pvalue is found to be 0.90 which means that the difference is statistically insignificant. Industry partners located outside the city/municipality of student-trainee's residence registered a slightly lower seriousness of problems encountered at 1.28 compared to industry partners within the city/municipality of student-trainee's residence with 1.36. The p-value is computed to be 0.48 which means that the difference is insignificant. Thus, the null hypothesis that there is no significant difference in seriousness of problems encountered during internship when grouped according to industry partner's profile is accepted.

Table 10. Relationship between Level of Implementation of Internship Program in Industry Partner, Student Interns' Feedback, Attainment of Program Objectives, and the Seriousness of Problems Encountered

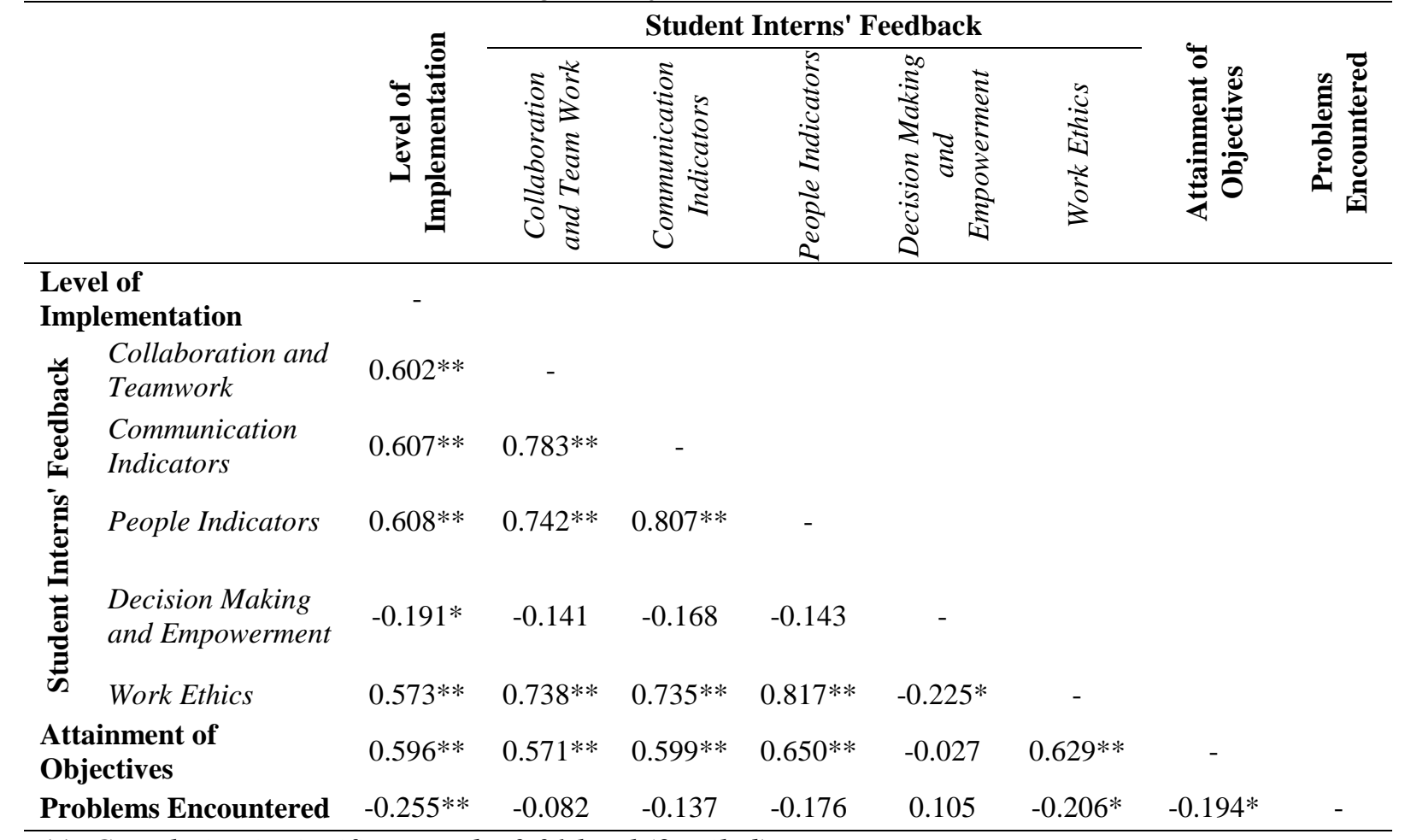

**. Correlation is significant at the 0.01 level (2-tailed).

*. Correlation is significant at the 0.05 level (2-tailed).

Table 11 presents the results of the correlation analysis conducted to determine the relationship between the level of implementation of internship program in industry partner, the students' feedback about the industry partner, the attainment of objectives, and the seriousness of problems encountered.
The study revealed a positive relationship between the level of implementation and four out of five areas of concern in terms of students' feedback on the industry partners namely collaboration and teamwork, people indicators, communication, and work ethics. The p-value was computed to be less than 0.01 indicating that the association between the variables were strong. The correlation coefficients computed to be at $0.602,0.607,0.608$, and 0.573 
respectively indicate that the relationship is moderate. The increase in the level of implementation of the internship program in the industry partner corresponds to an increase in the students' feedback on said areas. However, the level of implementation found an inverse relationship with the area of decision making and empowerment. It shows a negative relationship, albeit a weak one ( $\mathrm{r}=-$ $0.198, \mathrm{p}<0.05)$. Following the assertion made by Kasli and Ilban on the impact of problems encountered on attitude of interns towards jobs related to their field of study, it is more likely that the graduates of the Business Administration program will find a job in line with their course in the future due to the positive relationship between implementation and the low level of seriousness of problems encountered during their internship [12]

The level of implementation was also found to have a statistically significant relationship with the attainment of internship objectives with $p<0.01$. The relationship was found to moderately positive with $\mathrm{r}=0.596$. This indicates that an increase in the level of implementation of the internship program on the industry partner constitutes an increase in the level of attainment of internship objectives.

Further, the level of implementation was found to have a statistically significant relationship with the seriousness of problems encountered with $\mathrm{p}<0.01$. The relationship was determined to be a weak inverse one with $r=-0.255$. The inverse relationship indicates that the higher the level of implementation of internship program the less serious the problems encountered by interns become.

\subsection{Limitations of the Study}

The study is limited to the industry partners and students of the Business Administration program [15]. It can be replicated across other program offerings of the university to provide a more holistic assessment of the industry partners.

\section{Conclusion and Recommendations}

There is no difference in terms of the level of implementation of the internship program between PSU and the industry partners. The industry profile variables do not have any effect in terms of level of implementation, student-interns' feedback, attainment of objectives and seriousness of problems encountered. The level of implementation of internship program within the industry partner is related to the students' feedback on industry partners, attainment of internship objectives and problems encountered. It shows that the level of implementation enhances the perception of the students of industry partner with the exception of the area of decision making and empowerment. A stronger implementation of the internship program also contributes to the realization of internship objectives as well as minimization of the problems encountered. Our study is very important in Electric Power Systems and can find numerous applications in Electric Energy, Electric Vehicles Industry, Electric Economy etc.

The researcher recommends that the university maintain and sustain its partnership with current industry partners and expand its pool of linkages using its current industry partners' profile as the template for selection. In response to the strong commitment shown by the industry partners in ensuring the effective implementation of internship program, their inputs for improvement of the program should be given due consideration by the University and enhance the current training plan. The Memorandum of Agreement may be reviewed to improve the students' feedback on support provided by industry partners in the area of decision making and empowerment.

\section{Acknowledgments}

The researcher would like extend her gratitude to the President of Pangasinan State University, Dr. Dexter R. Buted, the Vice President for Research and Extension, Dr. Paulo V. Cenas, the Executive Director of the PSU Lingayen Campus, Dr. Lorna G. Urbiztondo, the Director for Public Relations, Publication and Information Office, Dr. Randy Joy M. Ventayen, and the faculty members of the Business Administration program. Most of all, I would like to dedicate this study to family, my husband Tony, and my dear son, Luke for inspiring me and making me feel loved each and every single day.

\section{References}

\section{7 pp. 1-5.}

[1] Bernarte R P Academe-Industry Partnership In The Philippines: Nature, Benefits And Problems, Vol.1, 2014.

[2] Kleibert J M, Industry-academe linkages in the Philippines: Embedding foreign investors, capturing institutions?, Geoforum, Vol.59, 2015, pp. 109-18.

[3] Vea R B, Philippine Institute for Development Studies.

[4] Commission on Higher Education CMO $104 \mathrm{s.}$ 2017 - CHED, 2017.

[5] Unterhalter E and Howell C, Unaligned 
connections or enlarging engagements? Tertiary education in developing countries and the implementation of the SDGs High. Educ. Vol.81 , 2021, pp. 9-29.

[6] Bridgstock R, The graduate attributes we've overlooked: Enhancing graduate employability through career management skills, High. Educ. Res. Dev., 2009.

[7] Caren Casama Orlanda-Ventayen and Rosario DL Valencerina, Employability Metrics of Bachelor of Secondary Education Graduates from 2013 to 2017: A Five Year of Findings and Analysis, Asian Journal of Multidisciplinary Studies, Vol.1, 2018.

[8] Anon Linking industry and academe | Inquirer Opinion.

[9] JS F and JP2 K, Building the relationship between industry and academia: Benefits and the general landscape of accomplishing research, J. Transl. Sci., Vol.4, 2017.

[10] Anon Challenges and expectations in academia and industry collaboration.

[11] Anon Symbiosis Between Academe and Industry.

[12] Pastor C K L, Sentiment Analysis on Synchronous Online Delivery of Instruction due to Extreme Community Quarantine in the Philippines caused by COVID-19 Pandemic, Asian J. Multidiscip. Stud., 2020.

[13] Ventayen R J M, Web Satisfaction Rating and Comparison of State University and Colleges Web Rankings, PSU J. Eng. Technol. Comput. Sci., 2017.

[14] Anon CHED Strengthens Academe-Industry Collaboration through Faculty Immersion | CHED K to 12 Transition Program.

[15] De Guzman M J J, Academe-Industry Partnership: Basis for Enhanced Learning of BSBA Students in One State University Univers. J. Educ. Res., Vol.8, 2020, pp. 657484.

[16] Rongshan Li, Yu Lu, Research on the Overoutsourcing in Aviation Manufacturing Industry - Case Analysis based on the Boeing 787, WSEAS Transactions on Business and Economics, pp. 505-513, Volume 17, 2020,
[17] Tzu-Kuang Hsu, Ming-Xiang Chen, MingLang Yeh, Ying-Shen Juang, Construct the Educational Training Model of the Taiwanese Bakery Industry by using Consistent Fuzzy Preference Relation Analytic Hierarchy Process, WSEAS Transactions on Business and Economics, pp. 1-5, Volume 17, 2020,

\section{Creative Commons Attribution License 4.0 (Attribution 4.0 International, CC BY 4.0)}

This article is published under the terms of the Creative Commons Attribution License 4.0

https://creativecommons.org/licenses/by/4.0/deed.en US 